\title{
SPATIAL DISTRIBUTION OF PRIMARY SCHOOLS AND THE NUMBER OF STUDENTS IN THE REPUBLIC OF MACEDONIA, WITH A SPECIAL FOCUS ON RURAL MUNICIPALITIES
}

DOI: http://dx.doi.org/10.18509/GBP.2016.43

UDC: 373.3.091.212.1(497.7-22)

\section{Sci. Marija Ljakoska \\ Full prof. Mirjanka Madjevikj, PhD}

University of "Ss Cyril and Methodius"-Skopje, Faculty of natural sciences and mathematics, Institute of geography, Skopje, Republic of Macedonia

\begin{abstract}
The period of transition in the Republic of Macedonia was followed by a number of reforms and intensive changes in all society spheres, as economy, science, health, and other, including education. The effect of these reforms in education was mostly felt in the changes of the number of primary schools and the number of students, especially in the number of students enrolled in first grade in the now days, nine-year primary education. The permanent trend of reduction in the number of pupils in primary schools, especially in schools that are within the territory of rural municipalities, caused a decrease in the number of classes, which often was the reason for the complete closure of schools. The total number of primary schools in the country, which in the school year 1998/99 was 1040 , decreased to 986 primary schools in the school year 2014/15, while the number of students decreased by 64467 in the same period.

This is due to the declining number of children that are forming the school contingent, as a result of the lower birth rates and the migratory movements of the population, primarily from rural to urban areas, but also, outside the country.

Following the number of pupils and the number of primary schools in terms of space is of great importance because that way we can plan future activities that would contribute to the demographic and overall development in a particular area.
\end{abstract}

Keywords: primary schools, students, rural municipalities, territorial distribution.

\section{INTRODUCTION}

Education is of the utmost importance in achieving sustainable development of the country, as it provides professional training and advancement of individuals as well as raising the quality of life and well-being of the whole society [10].

Considering the trends in the natural and population migration movement in the Republic of Macedonia, in a state of social, economic and political transition, we are witnessing the emergence of a separate phenomenon which refers to one of the main population contingents, and that is the population of school age. In circumstances when the education is compulsory and one of the basic guaranteed human rights, processes that suggest major changes and far-reaching consequences exactly in the number of persons who form this population contingent are occurring. What is notable is that year after year the extensive contingent in the past, gradually gets smaller and the available data indicate a worrying change in the scope of students who enroll in primary schools, from one school year into 
another. All this certainly has an impact on the socio-economic development of the country [6].

After the stabile state in the past that lasted until the 80s of the last century, when there were periods of increasing in the number of students despite the increase in the number of the total population in the country and the change in school-compulsory contingent, a few decades ago, there was a slowdown in the increase of the number of students, and in the last 17 years, a decrease in the number of students enrolled in primary schools.

About the importance of education, school contingent and generally, about the importance of researching on this issue, it has been discussed in the broader geographical literature. In fact, as fundamental geographic issues of the XXIst century, Newbold B., lists the environmental degradation, ethnic conflicts, health care, global climate change, the availability and level of education [9].

During the research on this issue from demogeographical aspect, it is not sufficient to take into account only the population and the number of students, but also the institutions in which the education is realized, the number and quality of staff participating in the educational process and the conditions in which this process occurs. For achieving greater access to education and a higher level of quality, very significant is the number and spatial distribution of schools, the number of professional staff, its workload and other. The research is focused on understanding the dynamic relationship that exists between the number of school-age population, the number of students, schools, classes and teachers especially in the rural municipalities. The aim of the research is to recognize the seriousness of this issue, to recognize the causes that lead to this situation and to point out what this means for the development of geospace, by analyzing the change in the size of the contingent of pupils in primary schools, especially in purely rural municipalities. It is very important to perceive the intensity with which changes are taking place, the development trends and their spatial differences, in which municipalities the problem is most pronounced, if somewhere do exist opportunities to improve the condition and so on.

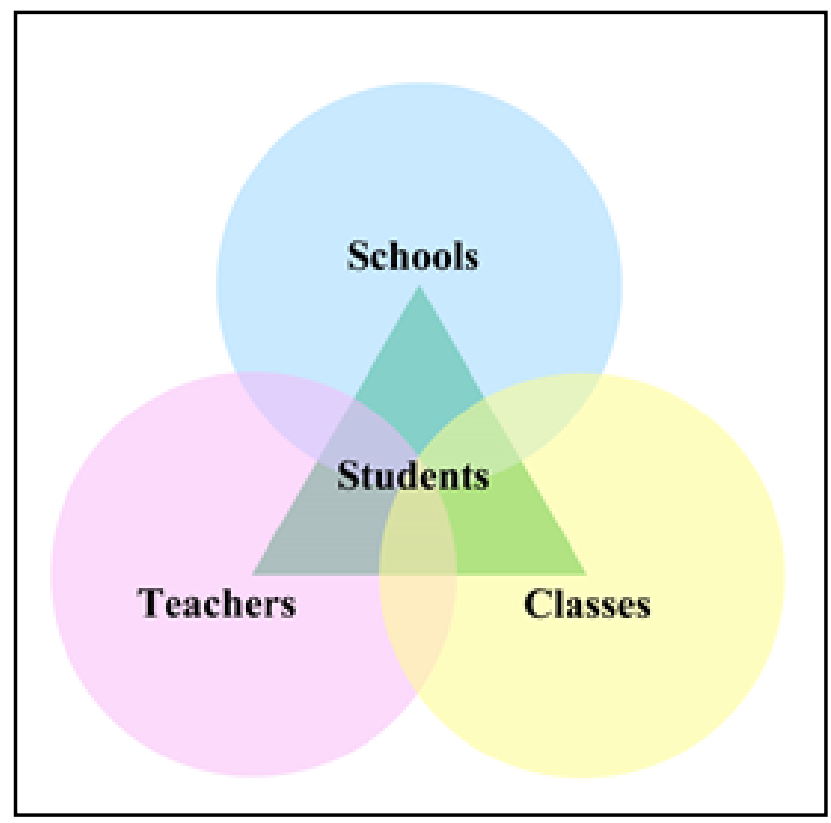

Figure 1. The connection between students, schools, teachers and classes 


\section{WORKING METHODS}

The studies that were done in order to prepare this paper are based on the modest researches done so far that come from professional elaboration in this area, which are mainly an integral part of a complex geographic research. Also, to form the basis of the statistical data on which is relying the detailed analysis of students, schools, classes and teachers were used official data from relevant institutions. The State Statistical Office of the Republic of Macedonia, through annual statistical surveys at the beginning and end of the school year, monitors the quantity of schools, students and teachers, as well as the completion of compulsory schooling for students [1]. The data are published regularly, every year in the publications titled "Primary and secondary schools at the beginning of the school year". The aim is to provide information on the status of regular primary education and all its characteristics and specificities [12].

In circumstances when we do not have recent census data on the number and structure of the population in order to find a contingent of the population that is or should be included in primary school are used data from publications about the "Estimates of the population by sex and age, by municipalities and statistical regions". From a methodological point of view, the differentiation of the municipalities as "rural" and "urban" is made depending on the status that the settlement has and which is determined as the head office of the municipality, depending on whether it is an urban or rural settlement. All of this is done on the basis of the territorial division from 2004 and the changes in the territorial organization applied in 2013, when four rural municipalities become part of the municipality of Kichevo with a head office in the city of Kichevo. These amendments directly reduce the number of rural municipalities. Taking into consideration the administrative-territorial organization of the country, we should mention that 37 out of now existing 80 municipalities have the head office set in a rural settlement which is $46.2 \%$, while in the period when the territory was divided into 123 municipalities, $68.3 \%$ were considered as rural [4].

In order to provide detailed analysis is used data from vital statistics and migration. According to the 2002 census in these municipalities lived $20.4 \%$ of the population in the country. In 16 pure rural municipalities, the number of births is equal to or less than the number of deaths and in 2014 in only 6 municipalities was registered a positive migration balance which reflected the overall demographic development.

Through the application of mathematical and statistical methods was made an analysis of the dynamics in the number of schools, students, teachers and classes and the trend of development of the municipalities in the Republic of Macedonia, but especially rural municipalities. The data for the rural municipalities refer to municipalities that during the analyzed year were included in the group of rural municipalities.

The application of the comparative method allows to compare the conditions of temporal and spatial terms, during the last 17 years, and to make mutual comparison of the situation in rural municipalities. As a limiting element occurs the lack of information on the number of students, according to certain marks such as the trend of students enrolled in the rural and urban area. Because of this, it is necessary required the collection and analysis of many data that by a mutual comparison would enable us to get a realistic image of the number and reallocation of students, teachers and schools within the rural area, ie outside the rural area. This condition is confirmed by the large number of teachers involved in the education system that due to the small number of students and classes, have to give lectures in several schools. 


\section{RESULTS AND DISCUSSION}

\section{DINAMICS AND DISTRIBUTION OF SCHOOLS AND STUDENTS}

The social, demographic, economic and political events in the late XX and the early XXI century resulted in changes in several areas of society and its development. As a special phenomenon that stands out for its importance is manifested in most parts of the country, and of course the consequences caused by the trend in the number of students who enroll in primary schools. The declining in the numbers of students intensifies and in the last 17 years, it can be felt in the whole republic, but it is particularly evident in the rural municipalities and smaller settlements. The change in the number of students is connected with elements that comprise the complex educational system and determines the number and distribution of schools, number and size of classes, etc. In Table 1 it can be noted that in the last period, the number of schools in the country decreased by $5.2 \%$, but worrying is the situation in rural areas where this reduction amounted to $34.2 \%$.

Table 1: Total number of schools and schools in the rural municipalities

\begin{tabular}{lcccccc}
\hline Schools/School year & $\mathbf{1 9 9 8 / 9 9}$ & $\mathbf{2 0 0 2 / 0 3}$ & $\mathbf{2 0 0 7 / 0 8}$ & $\mathbf{2 0 1 4 / 1 5}$ & $\begin{array}{c}\text { Index } \\
\mathbf{1 4 / 1 5}-\mathbf{9 8 / 9 9}\end{array}$ & $\begin{array}{c}\text { Index } \\
\mathbf{1 4 / 1 5}-\mathbf{0 7 / 0 8}\end{array}$ \\
\hline Total & 1040 & 1015 & 996 & 986 & 94.8 & 98.9 \\
\hline Rural municipalities & 539 & 518 & 393 & 355 & 65.8 & 90.3 \\
\hline Percentage share & $\mathbf{5 1 . 8}$ & $\mathbf{5 1}$ & $\mathbf{3 9 . 5}$ & $\mathbf{3 6}$ & - & - \\
\hline \multicolumn{7}{c}{$\begin{array}{c}\text { Source: SSO (1999-2015): Primary and secondary schools } \\
\text { at the beginning of the school year 1998/99 - 2014/15 }\end{array}$}
\end{tabular}

Because of the smaller number of students, especially in rural areas, many schools in the rural areas are closed. All of them were gradually closed due to emigration and the small number of children and because they could not be any activity in these areas without residents [8].

Table 2: Total number of students and students in the rural municipalities

\begin{tabular}{lcccccc}
\hline Students/School year & $\mathbf{1 9 9 8 / 9 9}$ & $\mathbf{2 0 0 2 / 0 3}$ & $\mathbf{2 0 0 7 / 0 8}$ & $\mathbf{2 0 1 4 / 1 5}$ & $\begin{array}{c}\text { Index } \\
\mathbf{1 4 / 1 5}-\mathbf{9 8 / 9 9}\end{array}$ & $\begin{array}{c}\text { Index } \\
\mathbf{1 4 / 1 5}-\mathbf{0 7 / 0 8}\end{array}$ \\
\hline Total & 256632 & 237581 & 222359 & 192165 & 74.9 & 86.4 \\
\hline Rural municipalities & 72636 & 52487 & 49289 & 37972 & 52.3 & 77 \\
\hline Percentage share & $\mathbf{2 8 . 3}$ & $\mathbf{2 2 . 1}$ & $\mathbf{2 2 . 2}$ & $\mathbf{1 9 . 7}$ & - & - \\
\hline \multicolumn{7}{c}{$\begin{array}{c}\text { Source: SSO (1999-2015): Primary and secondary schools } \\
\text { at the beginning of the school year 1998/99 - 2014/15 }\end{array}$}
\end{tabular}

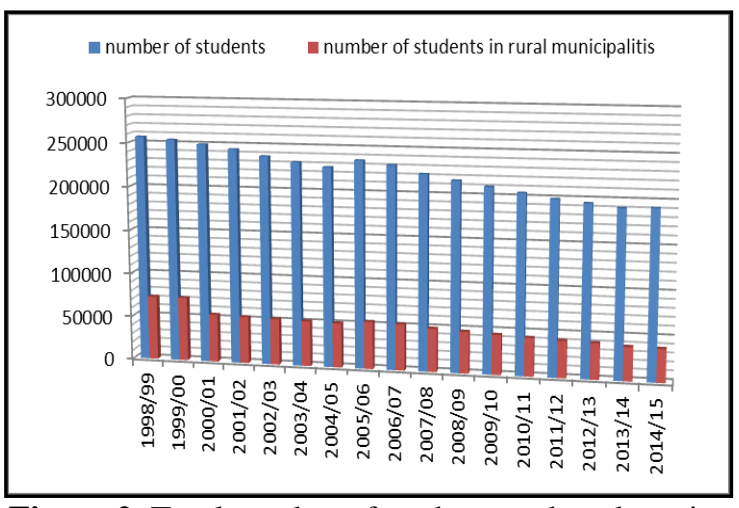

Figure 2. Total number of students and students in the rural municipalities

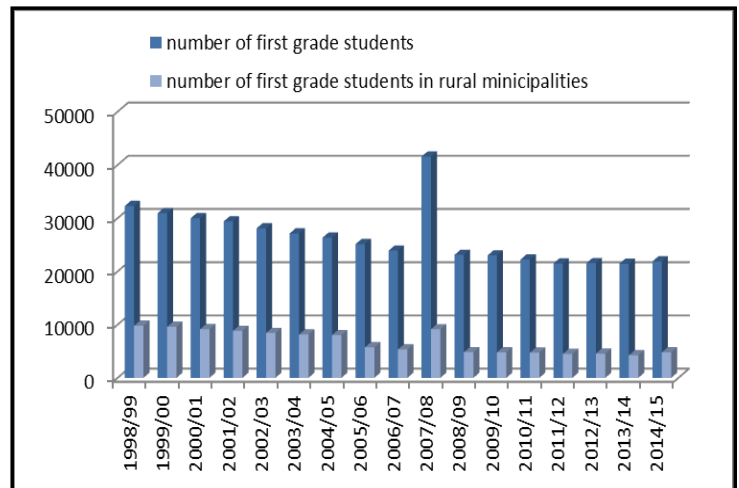

Figure 3. Total number of first grade students and first grade students in the rural municipalities 
The reduction is followed by a change in the territorial distribution of schools so if they contained more than half of the schools at the end of last century, today their percentage share declined to $36 \%$. The number of schools in the rural municipalities was reduced and on average, 10.8 schools were closed in each of the school years. This condition is associated with a reduction in the number of students and lower inflow of students of the new generations. The number of students in the rural municipalities decreases very quickly, ie $47.7 \%$, compared to those in the total number of municipalities where the number decreased by $25.1 \%$. This process does not stop even after 2007 when the new, nine year primary education was introduced ${ }^{2}$, which means one generation of students plus enrolled the primary school. Especially emphasized is the reduction in the number of first grade students, which is further reflected in the number of students in the coming years. With this problem are especially facing the municipalities in the Eastern, Vardar and Northeast region. The reasons for the decline in the number of students it can be clearly identified in the components that dictate the population dynamics, i.e. the natural and mechanical population movement. The transition of the population natural movement, with the dominant feature of the declining birth rate, it is one of the key moments that modifies the number of students, especially those enrolled in first grade, and it is still present in the remaining years of higher education.

\section{THE SIZE OF THE CLASSES AND THE NUMBER OF TEACHERS IN PRIMARY SCHOOLS}

According to the methodological normative for monitoring, a class is a group of students who are trained in the same room during the school year with one or more teachers, successively [1].

Table 3. Total number of classes and classes in the rural municipalities

\begin{tabular}{lcccccc}
\hline Classes/School year & $\mathbf{1 9 9 8 / 9 9}$ & $\mathbf{2 0 0 2 / 0 3}$ & $\mathbf{2 0 0 7 / 0 8}$ & $\mathbf{2 0 1 4 / 1 5}$ & $\begin{array}{c}\text { Index } \\
\mathbf{1 4 / 1 5}-\mathbf{9 8 / 9 9}\end{array}$ & $\begin{array}{c}\text { Index } \\
\mathbf{1 4 / 1 5}-\mathbf{0 7 / 0 8}\end{array}$ \\
\hline Total & 10291 & 10062 & 10647 & 10887 & 105.8 & 102.2 \\
\hline Rural municipalities & 3343 & 3297 & 2742 & 2585 & 77.3 & 94.7 \\
\hline Percentage share & $\mathbf{3 2 . 5}$ & $\mathbf{3 2 . 8}$ & $\mathbf{2 5 . 7}$ & $\mathbf{2 3 . 7}$ & - & - \\
\hline \multicolumn{7}{c}{$\begin{array}{c}\text { Source: SSO (1999-2015): Primary and secondary schools } \\
\text { at the beginning of the school year 1998/99 - 2014/15 }\end{array}$}
\end{tabular}

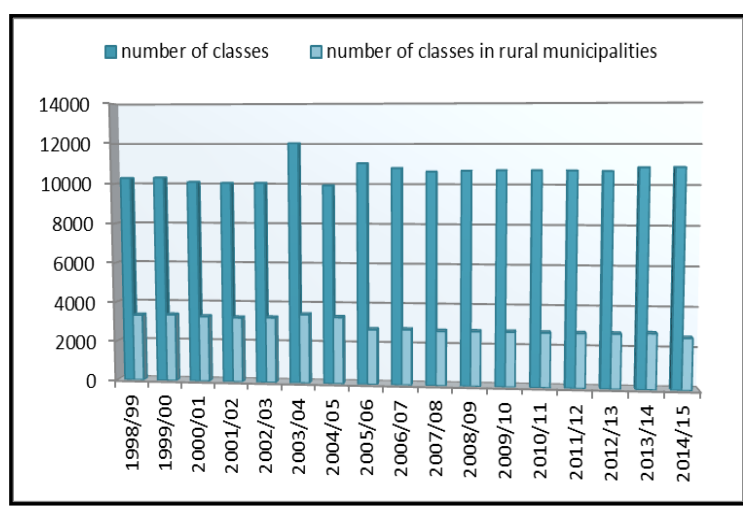

Figure 4. Total number of classes and classes in the rural municipalities

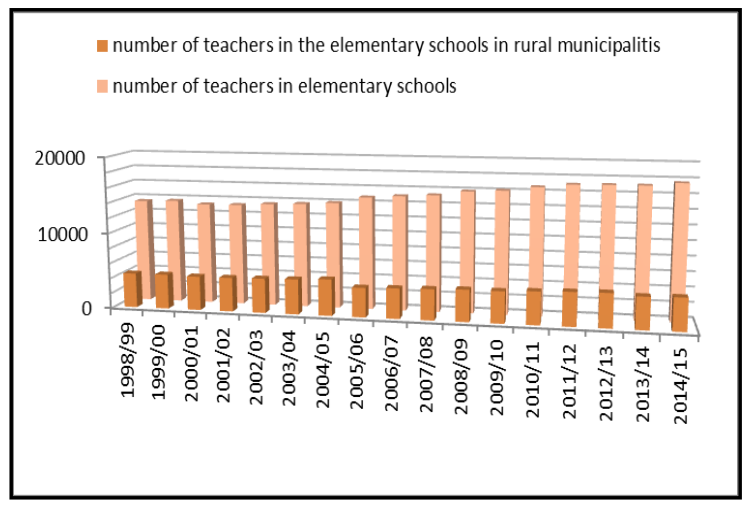

Figure 5. Total number of teachers and teachers in the rural municipalities

\footnotetext{
${ }^{2}$ Law Amending the Law on Primary Education, Official Gazette 63/2004 and 51/2007, Skopje pp 4-6 and pp 1-8
} 
The presented state of changes in the number of students is followed by corresponding changes in the number and size of classes. The trend of declining numbers of students contributes to reduce the number of classes in primary education and their average size now amounts 17.6 students and 14.7 students in the classes in rural municipalities.

The only positive change can be seen in the number of teachers who realize the educational programs by subjects. Because of the reforms in the educational system in the Republic of Macedonia and the new educational programs with an increased number of subjects there was a need of committing a higher number of teachers.

Table 4. Total number of teachers and teachers in the rural municipalities

\begin{tabular}{lcccccc}
\hline Teachers/School year & $\mathbf{1 9 9 8 / 9 9}$ & $\mathbf{2 0 0 2 / 0 3}$ & $\mathbf{2 0 0 7 / 0 8}$ & $\mathbf{2 0 1 4 / 1 5}$ & $\begin{array}{c}\text { Index } \\
\mathbf{1 4 / 1 5}-\mathbf{9 8 / 9 9}\end{array}$ & $\begin{array}{c}\text { Index } \\
\mathbf{1 4 / 1 5}-\mathbf{0 7 / 0 8}\end{array}$ \\
\hline Total & 13548 & 13590 & 15330 & 17628 & 130.1 & 114.9 \\
\hline Rural municipalities & 4524 & 4520 & 4054 & 4295 & 94.9 & 105.9 \\
\hline Percentage share & $\mathbf{3 3 . 4}$ & $\mathbf{3 3 . 3}$ & $\mathbf{2 6 . 4}$ & $\mathbf{2 4 . 4}$ & - & - \\
\hline \multicolumn{7}{c}{$\begin{array}{r}\text { Source: SSO (1999-2015): Primary and secondary schools } \\
\text { at the beginning of the school year 1998/99 - 2014/15 }\end{array}$}
\end{tabular}

The reasons for the changes in the number of students are distinct and generally associated with changes in the demographic structure of the population, the aging process and declining fertility, migration of younger population that is leaving rural area and moves towards urban centers in the country or abroad, etc. After all, one of the reasons for moving is exactly the small number of children who have not been enough for the sustainability of primary schools especially in peripheral rural areas. Back in the middle of the last century, when the migration from rural to urban areas become more intensive, start the closure of schools and for one part of the population, that was one of the reasons for resettlement and for another part of the population it was the reason that motivated them to move. The consequences of the spatial and demogeographical development are enormous. They directly affect the function of the educational institution's network, most of all, on those in elementary education. First, the size of the classes is reduced, the lectures for the students are held in combined classes and over time, the school fades away.

There is a need for additional efforts and financial resources due to a necessity for transporting students to schools in other settlements. The main characteristic is that the declineing number of students does not affect only subjects related to education, but it is in direct or indirect connection with other segments of society, such as the use and distribution of goods and services which are designed to meet the needs of students. They still need to be taken into account when making a detailed analysis of the situation in education and planning of specific activities related to students and other actors in the educational system [5].

The incomplete coverage of rural areas with schools mean different conditions for education. The survival of school it can be an element of settlement sustainability and retaining of the population. The contingent of the population aged 10 years and over in this century is quite stable and in rural areas does not exceed one-fifth of the total population. In the last decade in rural municipalities it can be observed a decrease of $3.6 \%$, which is partly due to the territorial administrative changes of 2013 . The size of the population contingent aged 5-14 years is important because it directly forms the contingent of the population in the primary education and determines the number of enrolled students. Among this population the situation is worrying. The total number of 
this population at the state level for the period 2002-2014 was estimated to have decreased by $23.8 \%$ and in the municipalities that are designated as purely rural the population number decreased by $53.1 \%$. This condition to a certain extent was affected by the administrative changes, but certainly by the trend in the components of the population dynamics. Interesting is the situation of the population under the age of 4 years because it is the population that in the coming years will form the influx of students in primary education. In the period 2002-2014, the contingent in the total number of population decreased by $5.4 \%$ and in rural areas $10.8 \%$. In the period 2007-2014 this contingent shows stabilization among of the overall population and among those living in rural municipalities.

The research shows the close relationship that exists between elements of the geographic system in which the population system through its subsystems can be separated from other geographical systems. The rural area with serious change is an example of how one part of the geographical system responds to changes occurring in the population.

\section{CONCLUSION}

For the purpose of fast and successful development of towns, regions and countries the educational level of the population is the matter of utmost importance. Monitoring the educational structure of the population enables timely, relatively simple planned and successfully conducted activities by which is possible to influence the development of the total population in a particular area. An educational background in one of the most important demographic factors of the overall development of a region. It can be concluded that despite the obvious progress in respect of the educational level of the population, this level is still not satisfactory. This is particularly true of smaller municipalities where there are no big cities, and which are far from major road links, and without any profitable industries [7].

In this paper are studied the number of children enrolled in primary education. The emphasis is given to the period from the beginning of the XXI century, and the data analysis suggests major changes in the contingent of students attending primary and secondary schools. The obtained information about this research shows the dynamic relationship between the age structure of the population, the number of students, classes and schools. The aim of the research is by analyzing the change in the size of the contingent of pupils in primary schools in the purely rural municipalities to see the dynamic interaction between them and the number of schools, teachers and classes and to recognize the seriousness of this issue and it further means for the spatial development as well as in which rural municipalities this problem is the most eloquent. They should find a practical application and have their place in creating policies directly related to the education of the population in rural areas, to contribute to the understanding of the relationship between population and geospace but also to the strengthening of demogeographical research methods on different territorial levels.

Rural settlements in modern conditions of development are facing numerous problems such as social, demographic, economic, infrastructural equipment, environmental protection, etc. The negative demographic development over the years has contributed to the decrease in total human potential in the County, as well as to the decrease in the number of pupils in classes and in the number of classes, which implies changes in the number and status of primary school units. Due to negative demographic trends that primarily took hold of rural areas in the Republic of Macedonia, as early as at the end of the XXIth century, a decline in the birth-rate and migrations from rural to urban areas, 
the question of ever growing number of combined classes and their organization is being raised [3].

Therefore, it is necessary to implement a series of measures that would have taken place in coordination with the population, local self government and relevant ministries.

Among the priority measures we would count the renovation of school buildings and the return of teachers. This measure is for the reason that the importance of the teacher in the rural environment is multiple: improving the educational level of the rural population, preventing the process of outflow of young people who later returned to the rural lifestyle, the teacher in the rural area indirectly educates older and also introduces innovations in terms of contemporary and cultural lifestyle [2].

The achieved level of education is an important element that is closely related to and conditioned by the development of a country. In the paper is presented the development path of this extremely important process, thus highlighted its main features and specifications.

\section{REFERENCES}

[1] Dikovska B. Primary schools in the urban-rural area (1973/74-1977/78), Review and study, No. 36 / XVIII, SSO, Skopje, pp 15-23, 1980

[2] Dimitrovska O. Sustainable development of rural areas in the Republic of Macedonia, Proceeding of the scientific symposium with international participation "Rural areas in the modern development conditions", Ohrid 2006, pp 701-712, 2006

[3] Leshcheshen I., Lj. Ivanovich Bibicha, A. Dragin, D. Balent. Problems of teaching organization in combined (Split) classes in rural areas of the Republic of Serbia, Geographica Pannonica, Vol. 17, Issue 2, pp 37-45, 2013

[4] Law amending the law on the territorial division of the Republic of Macedonia, 2004, 2008 and 2013

[5] Madjevikj M., Ljakoska M. Dynamics in the number of students in the Republic of Macedonia, Proceedings of the V Congress of geographers from the Republic of Macedonia, 26-29.IX.2015, Skopje, pp 115-124, 2015

[6] Madjevikj M. The educational structure of the population in the Republic of Macedonia, Geographical Review, Vol. 37, Skopje, pp 101-113, 2002

[7] Plavsha J. The Educational Structure of the Population of Vojvodina, Geographica Pannonica, Vol. 4, Novi Sad, 31-38, 2000

[8] Raguz M. Primary school, wrong way, Senjski zbornik, Vol. 26, pp 343-360, 2000

[9] Spasovski M., Danica Šantić. Development of population geography from anthropogeographical to spatial-analytical approach. Population, IDN CDI, Year LI, No. 2, Belgrade, 2013

[10] Zvezdanovich J. Education and development, Population 1/2013, Belgrade, pp 383, 2013

[11] SSORM 1999-2015: Primary and secondary schools at the beginning of the school year 1998/99 - 2014/15, Skopje

[12] SSORM 1980: Primary schools in SRM, according to urban-rural area, 1972/731977/78 school year, SSO, Skopje 